\title{
Phenotypes of the heavy chains of immunoglobulins in patients with diabetic microangiopathy: evidence for an immunogenetic predisposition
}

\author{
C MIJOVIC, J A FLETCHER, A R BRADWELL, A H BARNETT
}

\begin{abstract}
The B3 allotype of the fourth component of complement (C4B3) is associated with microangiopathy. As $\mathrm{C} 4$ is important in the humoral immune response phenotypic variation of other inherited components of the response such as the immunoglobulins could also be associated with microangiopathy. Phenotypes of the heavy chains of immunoglobulins $(\mathbf{G m})$ were compared in 48 insulin dependent diabetics with and 74 without microangiopathic complications. The Gm(zafnbg) phenotype was found significantly more often in insulin dependent diabetics with complications than in those without $(16(33 \%)$ out of $48 \mathrm{v}$ $7(9 \%)$ out of 74 , respectively, $p<0.01)$. Insulin dependent diabetics with both $\mathrm{C} 4 \mathrm{~B} 3$ and $\mathrm{Gm}(\mathrm{zafnbg})$ had an increased risk of complications compared with insulin dependent diabetics with neither or only one factor. Statistical analysis suggested that these two associations were additive, indicating that they increased risk by independent mechanisms.

These findings suggest that susceptibility to diabetic microangiopathy is influenced by genes at or in linkage disequilibrium with both the major histocompatibility complex and the $\mathrm{Gm}$ loci.
\end{abstract}

\section{Introduction}

Diabetic microangiopathy is a disease of the small blood vessels, clinically most apparent in the eyes and kidneys. Although duration of diabetes seems to be the most important factor for susceptibility,

\footnotetext{
Departments of Immunology and Medicine, University of Birmingham and East Birmingham Hospital, Birmingham

C MIJOVIC, BSC, research associate

J A FLETCHER, MRCP, research fellow

A R BRADWELL, FRCP, senior lecturer and honorary consultant immunologist A H BARNETT, MD, MRCP, senior lecturer and honorary consultant physician

Correspondence to: Miss C Mijovic, Department of Immunology, University of Birmingham, Birmingham B15 2TJ.
}

$20 \%$ of insulin dependent diabetics do not develop complications even after 30 years of having had the disease. ${ }^{1}$ Quality of diabetic control is probably important, ${ }^{2}$ but there is evidence that immunogenetic factors may have a role in its pathogenesis. HLA associations with $\mathrm{B} 8, \mathrm{~B} 15$, and $\mathrm{DR} 4$ and retinopathy have been reported, but results of other studies are conflicting. ${ }^{1}$

The fourth component of complement (C4) is also coded for in the HLA region at two loci, $\mathrm{C} 4 \mathrm{~A}$ and $\mathrm{C} 4 \mathrm{~B}$. Both are highly polymorphic; 13 different alleles have been described for the $A$ locus and 22 for the $\mathrm{B}$, including a null (silent) allele at each locus. ${ }^{3}$ We have previously shown an association between the B3 allotype of $\mathrm{C} 4$ and microangiopathy. ${ }^{4} \mathrm{C} 4$ is important in the humoral immune response, and if this is relevant to the pathogenesis of microangiopathy then the immunoglobulin genes could also be important. The constant regions of the IgG heavy chains are coded for on chromosome 14 at the closely linked Gm loci for markers on IgG1, IgG2, and IgG3. ${ }^{5}$ We therefore examined $\mathrm{Gm}$ phenotypes in insulin dependent diabetics with and without microangiopathy.

\section{Subjects and methods}

A total of 122 northern European insulin dependent diabetics (prone to ketosis) were studied: 48 had microangiopathy (mean age 36.4 years, range 18-63; mean duration of diabetes $20 \cdot 4$ years, range $7-39$ ) and 74 did not (mean age $27 \cdot 8$ years, range $14-56$; mean duration $12 \cdot 1$ years, range $1-38$ ). Patients were examined for retinopathy by ophthalmoscopy, through dilated pupils, by two independent and experienced clinicians. Neuropathy (clinical methods only) and concentration of urine albumin (using Albustix) were also assessed. Subjects without any evidence of complications were classified as having no microangiopathy. Subjects classified as showing microangiopathy had retinopathy with or without proteinuria or neuropathy.

Plasma samples containing edetic acid were typed blind for $\mathrm{Gm}$ markers using a standard haemagglutination inhibition assay. ${ }^{6}$ Each sample was tested in dilutions of 1 in 20 and 1 in 60 using antisera from the Netherlands Blood Transfusion Service. Typing was carried out for the following heavy chain markers on $\operatorname{IgG}$ subclass $1: \operatorname{Glm}(\mathrm{z}), \mathrm{Glm}(\mathrm{a}), \mathrm{Glm}(\mathrm{x})$, and $\mathrm{G} \operatorname{lm}(\mathrm{f})$; IgG subclass 2: $\mathrm{G} 2 \mathrm{~m}(\mathrm{n})$; and $\operatorname{IgG}$ subclass $3: \mathrm{G} 3 \mathrm{~m}(\mathrm{bl})$ and $\mathrm{G} 3 \mathrm{~m}(\mathrm{~g})$. This allowed identification of the common haplotypes of white people $\mathrm{Gm}(\mathrm{zag})$, $\mathrm{Gm}(\mathrm{zaxg}), \mathrm{Gm}(\mathrm{fb})$, and $\mathrm{Gm}(\mathrm{fnb})$.

$\mathrm{C} 4$ typing was performed by agarose electrophoresis and immunofixation as described previously. ${ }^{4}$ 


\section{STATISTICAL ANALYSIS}

As the mean durations of disease in the two groups of insulin dependent diabetics with and without microangiopathy were different the 48 insulin dependent diabetics with complications were paired as closely as possible for duration with 48 insulin dependent diabetics without complications. Pairing was done without knowledge of the $\mathrm{Gm}$ phenotypes. The McNemar test was used to calculate any statistical differences between the frequencies of the various $\mathrm{Gm}$ phenotypes in the two groups. The $\mathrm{p}$ values calculated were corrected for the number of tests performed by multiplication by the number of phenotypes compared.

The $\chi^{2}$ test was used to calculate the significance of differences in frequencies of $\mathrm{Gm}$ phenotypes between the 48 insulin dependent diabetics with complications and the 74 without. The $\mathrm{p}$ values calculated were corrected as above.

The method of iterative proportional fitting for log linear models was used to test for any interaction between the $\mathrm{Gm}$ loci, the $\mathrm{C} 4$ loci, and microangiopathy. The unmatched population gave comparable results to those from the duration matched pairs; as it was larger the analysis for interaction was done using the total population studied. Expected numbers (assuming no three way interaction) were calculated by this method for insulin dependent diabetics with and without microangiopathy possessing either, both, or neither risk factor. These were then used in a three way contingency table to test the null hypothesis of no three way interaction using the $\chi^{2}$ and $\mathrm{G}^{2}$ (goodness of fit) statistics to test for differences in the observed and expected numbers. ${ }^{78}$

The odds ratio (cross product ratio for $2 \times 2$ contingency tables) was calculated for possession of either or both C4B3 and Gm(zafnbg) compared with possession of neither. As the prevalence of microangiopathy is appreciable in the diabetic population the odds ratio provides only an estimation of the relative risk.

\section{Results}

The matched pair analysis of the groups of 48 insulin dependent diabetics with and 48 without microangiopathy showed a significant increase in the frequency of the heterozygous $\mathrm{Gm}$ (zafnbg) phenotype in the group with complications $(p<0.005$; with correction for the number of phenotypes compared (nine) $p<0.05)$. The $\mathrm{Gm}(\mathrm{zafnbg})$ phenotype was found in only the patient with complications in 15 pairs of patients, only the patient without complications in three pairs, both patients in one pair, and in neither patient in 29 pairs.

There was a significant increase in frequency of the phenotype Gm(zafnbg) in the group of insulin dependent diabetics with microangiopathy compared with those without (16 (33\%) out of $48 v 7(9 \%)$ out of 74 , respectively, $\chi^{2}=10.84, p<0.001$, corrected $\left.p<0.01\right)$. There was no significant difference in the frequency of any of other phenotypes between the two groups (table I).

TABLE I-Frequencies of $\mathrm{Gm}$ phenotypes in insulin dependent diabetics with and without microangiopathy

\begin{tabular}{lccc}
\hline & $\begin{array}{c}\text { No (\%) of } \\
\text { insulin dependent diabetics } \\
\text { with microangiopathy } \\
(\mathbf{n}=48)\end{array}$ & $\begin{array}{c}\text { No(\%) of } \\
\text { insulin dependent diabetics } \\
\text { without microangiopathy } \\
(\mathbf{n}=74)\end{array}$ & $\begin{array}{c}\mathbf{p} \text { Value } \\
\text { (corrected) }\end{array}$ \\
\hline Phenotype & $16(33)$ & $7(9)$ & $<0 \cdot 001(<0 \cdot 01)$ \\
zafnbg & $14(29)$ & $32(43)$ & NS \\
fnb & $5(10)$ & $12(16)$ & NS \\
zafb & $4(8)$ & $5(7)$ & NS \\
fb & $4(8)$ & $4(5)$ & NS \\
zaxg & $2(4)$ & $6(8)$ & NS \\
zaxfbg & $1(2)$ & $6(8)$ & NS \\
zaxfnbg & $1(2)$ & $1(1)$ & \\
zag & $1(2)$ & $1(1)$ & \\
zafnb & & &
\end{tabular}

* $\mathrm{b}$ refers to the bl allotype.

Table II gives the frequency of the C4B3 allotype and the Gm(zafnbg) phenotype in insulin dependent diabetics with and without microangiopathy and statistical analysis of the interaction between these two risk factors and microangiopathy. The $p$ values from the $\chi^{2}$ and the $G^{2}$ tests were not significant, which is consistent with there being no interaction between $\mathrm{C} 4 \mathrm{~B} 3$ and $\mathrm{Gm}$ (zafnbg) in relation to microangiopathy. This indicates that the effect of these two factors on the risk of development of microangiopathy was additive. An odds ratio of 1 was assigned to subjects with neither risk factor and compared with this subgroup the odds ratio was $2 \cdot 9$ for subjects with C4B3, 4.9 for those with $\mathrm{Gm}$ (zafnbg), and 14.4 for those with both.
TABLE II-Statistical analysis for interaction between C4B3, Gm(zafnbg), and microangiopathy

\begin{tabular}{|c|c|c|c|c|c|c|}
\hline \multirow[b]{2}{*}{ C4B3 } & \multirow[b]{2}{*}{ Gm(zafnbg) } & \multicolumn{2}{|c|}{$\begin{array}{l}\text { Insulin dependent diabetics } \\
\text { with microangiopathy } \\
(\mathrm{n}=48)\end{array}$} & \multicolumn{2}{|c|}{$\begin{array}{l}\text { Insulin dependent diabetics } \\
\text { without microangiopathy } \\
\qquad(\mathrm{n}=74)\end{array}$} & \multirow[b]{2}{*}{$\begin{array}{l}\text { Odds } \\
\text { ratio }\end{array}$} \\
\hline & & $\begin{array}{c}\text { No (\%) } \\
\text { observed }\end{array}$ & $\begin{array}{c}\text { No } \\
\text { expected }\end{array}$ & $\begin{array}{c}\text { No (\%) } \\
\text { observed }\end{array}$ & $\begin{array}{c}\text { No } \\
\text { expected }\end{array}$ & \\
\hline+ & + & $4(8)$ & 3.41 & 0 & 0.59 & 14.4 \\
\hline- & + & $12(25)$ & $12 \cdot 60$ & $7(9)$ & 6.41 & 4.9 \\
\hline+ & - & $7(15)$ & $7 \cdot 58$ & $7(9)$ & 6.42 & $2 \cdot 9$ \\
\hline - & - & $25(52)$ & $24 \cdot 40$ & $60(81)$ & 60.6 & 1.0 \\
\hline
\end{tabular}

$+=$ Present.$-=$ Not present

Significance of three way interaction (see statistical analysis): $\chi^{2}=0.89(p>0.05) ; G^{2}=1.46$ $(\mathrm{p}>0.05)$.

\section{Discussion}

We have previously reported an association between $\mathrm{C} 4 \mathrm{~B} 3$ and the development of microangiopathy. Our present results indicate a further association with the immunoglobulin $\mathrm{Gm}$ phenotype (zafnbg). In addition, statistical analysis suggested that these factors were additive and therefore independent risk factors. Clearly, these findings are important to the understanding of microangiopathy. Although it is considered that metabolic control influences the development of the disease, our results show that immune factors may be important. The action of such genes may partly explain the variable rate of development of microangiopathy in patients with apparently similar control.

Many studies have tried to assess the relation between $\mathrm{Gm}$ types and immune responsiveness. In two studies the $\mathrm{Gm}$ (zagx) haplotype has been found to be associated with the presence of antibodies to insulin. ${ }^{910}$ High titres of these antibodies have been associated with microangiopathy, ${ }^{11}$ but this finding is not well established. ${ }^{12}{ }^{13}$ There is experimental evidence that the capacity for an amplified immune response to bacterial antigen is conferred by heterozygosity for $\mathrm{Gm} .{ }^{14}$ This may lead to increased levels of circulating immune complexes. High levels of these have also been associated with the presence of microangiopathy, ${ }^{12}{ }^{13}$ but there is no evidence to suggest whether this is cause or effect.

There are several explanations for our findings. Firstly, the Gm variants could have a direct effect on the development of microangiopathy, but as the amino acid substitutions so far determined have no known functional effect this is unlikely. Secondly, the effect could be due to other immune function genes nearby that are in linkage disequilibrium with the $\mathrm{Gm}$ locus. Such genes include those coding for the immunoglobulin heavy chain variable regions and probably immune regulatory genes. Any of these could have an effect on immune responsiveness. The $\mathrm{Gm}$ (zafnbg) phenotype may cause an enhanced immune response to vascular antigens that have been rendered immunogenic by damage initiated by metabolic disturbance. This could lead to local deposition of immunoglobulins and further vascular damage. Thirdly, there could be linkage disequilibrium with non-immune genes, but as little is known about such neighbouring genes this explanation is speculative.

We conclude that in addition to an HLA linked factor, we have identified a non-HLA linked genetic factor associated with susceptibility to diabetic microangiopathy. Our findings suggest that there is an immunogenetic component of the aetiology of these complications, which may help to identify a subset of insulin dependent diabetics predisposed to microangiopathy.

We thank the British Diabetic Association, the West Midlands Regional Research Committee, and Nordisk UK for financial support; Dr D McDonald for advice on the technique of $\mathrm{Gm}$ typing and for supplying the $\mathrm{G} 2 \mathrm{~m}(\mathrm{n})$ sensitised indicator cells; $\mathrm{Dr} R$ Holder for help with the statistical analysis; and $\mathrm{Mr} \mathrm{T}$ Marshall for useful discussion.

\section{References}

1 Barbosa J, Saner B. Do genetic factors play a role in pathogenesis of microangiopathy? Diabetologia 1984;27:487-92.

2 Tchobroutsky G. Relation of diabetic control to development of microvascular complications. Diabelologia 1978;15:143-52. 
3 Mauff G, Alper CA, Awdeh Z, et al. Statement on the nomenclature of human C4 allotypes. Immunobiology 1983;164:184-91.

4 Mijovic C, Fletcher J, Bradwell AR, Harvey T, Barnett AH. Relation of gene expression (allotypes) of the fourth component of complement to insulin dependent diabetes and its (allotypes) of the fourth component of complement to

5 Pandey JP, Whitten HD, Fudenberg HH. Genetics of human immunoglobulins. In: Panayi GS, David CS, eds. Immunogenetics. London: Butterworths, 1984:92-109.

6 Propert DN. Detection of immunoglobulin polymorphisms. In: Simons MJ, Tait BD, eds. Detection of immune-associated genetic markers of human disease. London: Churchill Livingstone, 1984:65-81.

7 Brown MB. Frequency tables-P4F. In: Dixon WJ, ed. BMDP statistical software, 1983. Berkeley: University of California Press, 1983

8 Mathews JD. Statistical aspects of immunogenetic associations with disease. In: Simons MJ, Tait BD, eds. Detection of immune associated genetic markers of human disease. London: Churchill Livingstone, 1984:106-36.

9 Nakao $\mathrm{Y}$, Matsumoto $\mathrm{H}$, Miyazaki T, et al. IgG heavy chain $(\mathrm{Gm})$ allotypes and immune response to insulin in insulin requiring diabetes mellitus. $N$ Engl f Med 1981;304:407-9.
10 Reeves WG, Barr D, Douglas CA, et al. Factors governing the human immune response to injected insulin. Diabetologia 1984;26:266-71.

11 Andersen OO. Anti-insulin antibodies and late diabetic complications. Acta Endocrinol 1976;83: $329-40$.

12 DiMario U, Ventriglia L, Iavicoli M, Guy K, Andreani D. The correlation between insulin antibodies and circulating immune complexes in diabetics with and without microangiopathy. Clin Exp Immunol 1983;52:575-80.

13 Bodansky HJ, Wolf E, Cudworth AG, et al. Genetic and immunologic factors in microvascular disease in type 1 insulin dependent diabetes. Diabetes 1982;31:70-4.

14 Whittingham S, Mathews JD, Schanfield MS, et al. Interactive effect of Gm allotypes and HLA B locus antigens on the human antibody response to a bacterial antigen. Clin Exp Immunol $1980 ; 40: 8-15$

(Accepted 10 December 1985)

\title{
Prostacyclin deficiency in a young woman with recurrent thrombosis
}

\author{
JOHN G LANHAM, MICHAEL LEVIN, ZARIN BROWN, AZZIZ E GHARAVI, \\ PAUL A THOMAS, GILLIAN C HANSON
}

\begin{abstract}
A young woman with recurrent deep venous thromboses and spontaneous abortions was studied. She suffered an ovarian infarction followed by aortic thrombosis and renal failure. Evidence for deficient prostacyclin production was found and she responded to treatment with a prostacyclin infusion. This syndrome is identical with that seen in women with the lupus anticoagulant, but the lupus anticoagulant was not detected and no other cause was identified.
\end{abstract}

\section{Introduction}

A syndrome of recurrent deep venous and arterial thromboses with recurrent spontaneous abortions has been described in young women with the lupus anticoagulant. ${ }^{1}$ The lupus anticoagulant may be implicated in the pathogenesis of this syndrome through suppression of prostacyclin production. ${ }^{23}$ We report a young woman with a similar syndrome, when life threatening arterial thrombosis occurred. No prostacyclin production by her own arterial tissue could be shown and reduced prostacyclin activity was found when umbilical cord artery and rat aortic tissue were incubated in her plasma. She did not have the lupus anticoagulant or any other disorder associated with arterial thrombosis.

Whipps Cross Hospital, London E11 1NR

JOHN G LANHAM, MB, MRCP, consultant physician and rheumatologist

PAUL A THOMAS, MB, FRCS, consultant surgeon

GILLIAN C HANSON, MB, FRCP, consultant physician

Hammersmith Hospital, London W12 0HS

AZZIZ E GHARAVI, MD, honorary clinical assistant

Institute of Child Health, London WC1N IEM

MICHAEL LEVIN, MB, MRCP, lecturer

Renal Unit, Guy's Hospital, London SE1 9RT

ZARIN BROWN, BSC, research technician

Correspondence to: Dr Lanham.

\section{Case report}

A 25 year old woman with no family history of thrombotic disease first took the oral contraceptive pill when aged 17, and six months later suffered bilateral deep vein thromboses and a pulmonary embolus. At the age of 23 she had a spontaneous abortion at eight weeks. One year later a second pregnancy was complicated by a left leg deep vein thrombosis at 26 weeks, and this pregnancy terminated with an intrauterine death at 31 weeks. Placental histology showed vascular insufficiency to be the cause. A third pregnancy ended in spontaneous abortion at 24 weeks, despite treatmen with subcutaneous heparin for the first 16 weeks followed by treatment with warfarin. Subcutaneous heparin (10000 units daily) was begun again after the abortion, but 10 days later she developed a right iliofemoral vein thrombosis. The heparin dose was increased, but a fortnight thereafter she required a laparotomy because of a ruptured right tubo-ovarian cyst; histological examination showed infarcted ovarian and paraovarian tissues.

Three weeks later, while still receiving heparin, she presented with an ischaemic left foot with absent leg pulses and an abdominal aortic bruit. At emergency laparotomy thrombus was found in the aorta and both iliac and femoral arteries (figure). This was removed and she was again fully heparinised. Postoperatively she developed acute renal failure and subsequently septicaemia and required ventilation. Her renal failure was attributed to extension of the thrombus into the renal arteries and a prostacyclin (epoprostenol) infusion was therefore begun. Thereafter, renal function improved rapidly as did perfusion of the right foot. The left foot remained ischaemic and was eventually amputated below the knee. On reduction of the dose of epoprostenol she developed severe bilateral leg oedema, which was ascribed to a partial inferior venacaval thrombosis. With an increased dose the oedema gradually subsided and the epoprostenol and heparin infusions were stopped a month later.

Treatment with warfarin, paediatric aspirin, and dipyridamole was started. Renal function returned to normal. At no time were there any clinical features to suggest a connective tissue disease or vasculitis.

Full blood count and erythrocyte sedimentation rate were normal during her third pregnancy but the platelet count rose from 250 to $640 \times 10^{9} / 1$ at the time of the aortic thrombosis. Before treatment her prothrombin time and partial thromboplastin time were normal. To confirm that she did not have the lupus anticoagulant a plasma sample was fractionated and lupus anticoagulant activity was sought, but not found, in the IgG and IgM fractions (method of Boey et $a l^{1}$ ). Fibrinogen, fibrinogen degradation products, and antithrombin III were also normal. Protein $\mathrm{C}$ concentration (chromogenic assay) was depressed but compatible with treatment with warfarin and did not suggest a congenital deficiency. No antibodies to nuclear antigens, deoxyribonucleic acid, extractable nuclear antigens, or cardiolipin were detected. Lipid concentrations were normal and screening for homocystinuria was negative. Histological examination of the aorta and tibial artery showed intraluminal thrombosis, but the vessel wall was normal, and no evidence of atheroma, vasculitis, or thrombotic thrombocytopenic purpura was found. 